\title{
Vaccination against feline immunodeficiency virus using fixed infected cells
}

\author{
E.J. Verschoor ${ }^{a} *$, A.L.W. van Vliet $^{\mathrm{a}}$, H.F. Egberink ${ }^{\mathrm{a}}$, W. Hesselink ${ }^{\mathrm{c}}$, \\ W.E. van Alphen ${ }^{b}$, I. Joosten ${ }^{b}$, C.J.P. Boog ${ }^{b}$, M.C. Horzinek ${ }^{a}$, \\ A. de Ronde \\ "Virology Division, Department of Infectious Diseases and Immunology, Veterinary Faculty, University Utrecht. \\ Yalelaan 1, 3584 CL Utrecht, The Netherlands \\ ${ }^{\mathrm{h}}$ Institute of Immunology, Department of Infectious Diseases and Immunology, Veterinary Facultv, \\ University Utrecht. The Netherlands \\ 'Intervet International BV. Boxmeer, The Netherlands
}

\begin{abstract}
Crandell feline kidney cells and feline thymocytes, either feline immunodeficiency virus (FIV) infected or uninfected, were fixed with paraformaldehyde and used to vaccinate cats. The cells were mixed with a $30: 70$ water/mineral oil emulsion containing $250 \mu \mathrm{g} \mathrm{ml}^{-1} N$-acetyl-D-glucosaminyl$\beta$-(1-4) - $N$-acetyl-muramyl-L-alanyl-D-isoglutamine. Eighteen specific pathogen-free cats were vaccinated three times with 3 -week intervals and challenged 21 days after the final boost with a low dose of the homologous FIV-UT1 13 strain. Eight out of ten cats that had received FIV-infected cell vaccines developed significant anti-FIV antibody titres to the envelope and core antigens. Neutralizing antibodies were detectable at the moment of challenge in the sera of these animals. Within 5 weeks after challenge 15 out of 18 cats became viraemic. Three animals, two that had been vaccinated with FIVinfected thymocytes and did not develop antibody, and one that had received an uninfected thymocyte preparation, remained uninfected for 6 months. Upon rechallenge of the three animals, two again resisted infection; these cats had been immunized with the infected and the uninfected thymocyte preparations, respectively.
\end{abstract}

\section{Abbreviations}

AIDS, acquired immune deficiency syndrome; ID-IEF, one-dimensional isoelectric focusing; FCS, foetal calf serum; FIV, feline immunodeficiency virus; G-MDP, $N$-acetyl-D-glucosaminyl- $\beta-(1-4)$ $\mathrm{N}$-acetyl-muramyl-L-alanyl-D-isoglutamine; IFA, immunofluorescence assay; $\mathrm{MHC}$, major histocompatibility complex; PBLs, peripheral blood lymphocytes; PBS, phosphate-buffered saline; PCR, polymerase chain reaction; RT, room temperature; SIV, simian immunodeficiency virus; SPF. specific pathogen-free; VN antibodies, virus-neutralizing antibodies.

\footnotetext{
* Corresponding author. Tel: 31-30-534195; Fax: 31-30-536723.
} 


\section{Introduction}

Feline immunodeficiency virus (FIV) is a lentivirus that causes acquired immune deficiency syndrome (AIDS) in cats. The virus occurs worldwide in the cat population with infection rates varying from 1 to $15 \%$ in healthy animals; FIV can thus be considered as an important pathogen in cats (Egberink and Horzinek, 1992). Development of an effective vaccine against FIV infection is therefore of veterinary importance. In addition, like simian immunodeficiency virus (SIV) in macaques, FIV infection in cats is an animal model for human AIDS; FIV vaccine trials could contribute to the development of a successful and safe vaccine against HIV.

Protection of macaques against SIV infection has been reported using inactivated whole virus or fixed-infected cell vaccines, but also virion subunits and attenuated SIV have been found effective (Daniel et al., 1992; Hu et al., 1992; Johnson et al., 1992). Also for FIV, successful vaccine trials have been reported. Inactivated whole virus and paraformaldehydefixed FIV-infected cells have been used to protect cats against challenge with a homologous (Yamamoto et al., 1991) and a heterologous virus strain (Yamamoto et al., 1993).

The aim of this study was to investigate the efficacy of vaccines prepared from the Dutch isolate FIV-UT113 grown in two cell types.

\section{Materials and methods}

\subsection{Preparation and titration of challenge virus}

The strain FIV-UT113 had been isolated from peripheral blood lymphocytes (PBLs) of a seropositive, naturally infected cat. The virus challenge stock was prepared in thymocytes from a specific pathogen-free (SPF) cat. Cells were stimulated with $5 \mu \mathrm{g} \mathrm{ml}^{-1}$ Concanavalin A and cultured in RPMI-1640 medium containing 10\% foetal calf serum (FCS) and 200 units recombinant human interleukin-2 $\mathrm{ml}^{-1}$ (rIL-2; Proleukin, Eurocetus). Thymocytes were then infected and incubated for 5 days. Cell-free culture supernatant was collected, and dilutions of the challenge stock were aliquoted and stored at $-80^{\circ} \mathrm{C}$.

Five-month-old SPF cats were used for in vivo titration of the challenge stock. One millilitre of virus dilution was inoculated subcutaneously (s.c.) using two cats for each dilution. Infection was monitored using virus isolation from PBLs and seroconversion. The undiluted challenge stock was estimated to contain $3 \times 10^{4}$ cat infectious doses $50 \%\left(\mathrm{CID}_{50}\right)$ per ml.

\subsection{Preparation of vaccines}

Crandell feline kidney cells (CRFK cells), either uninfected or persistently infected with FIV-UT113 (80\% infected cells) (Egberink et al., 1990) were resuspended in phosphatebuffered saline (PBS) containing 0.02\% EDTA. The cells were collected by low-speed centrifugation, washed once with PBS and fixed with paraformaldehyde as described by Yamamoto et al. (1991). To prepare a batch of FIV-infected thymocytes, aliquots of $10^{6}$ cells were infected with FIV-UT113. After 4 days, the primary cultures were used to infect 
a larger batch of cells that was incubated for several days till a maximum (25\%) of infected cells was obtained. Expansion of the infected thymocyte culture was repeated till enough cells had been obtained to prepare the vaccine. Fixation of the cells was performed as described for the CRFK vaccines. The preparations were mixed with an adjuvant consisting of a 30:70 water/mineral oil emulsion containing $250 \mu \mathrm{g} \mathrm{ml}^{-1} \mathrm{~N}$-acetyl-D-glucosaminyl$\beta$ - (1-4) - $N$-acetyl-muramyl-L-alanyl-D-isoglutamine (G-MDP). Each dose of vaccine consisted of $2.5 \times 10^{7}$ cells in $1 \mathrm{ml}$ of adjuvant.

\subsection{Vaccination protocol}

Nineteen 4-month-old SPF cats received threc intramuscular vaccinations with 21-day intervals. Five cats were immunized with three vaccine doses of the FIV-infected CRFK cells and three cats received three doses of the uninfected CRFK vaccine. Cats immunized with the thymocyte vaccines were given a first vaccination with one complete dose, followed by two booster vaccinations with $1.25 \times 10^{7}$ fixed cells. Five cats received the thymocyteUT113 vaccine and three cats were immunized with uninfected thymocytes. Three cats served as PBS controls. Three weeks after the last booster immunization all cats were subcutaneously challenged with 10 CID $_{50}$ of FIV-UT113.

\subsection{Virus isolation}

PBLs were isolated from samples of EDTA blood by Ficoll-Hypaque gradient centrifugation, stimulated with $5 \mu \mathrm{g} \mathrm{ml}^{-1}$ Concanavalin A for $24 \mathrm{~h}$ and cultured in RPMI-1640

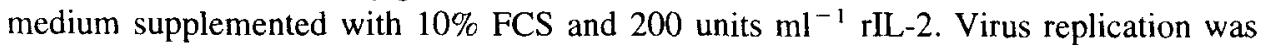
measured using a p24 ELISA.

\subsection{Serological assays}

Titres of FIV-specific antibodies were determined by ELISA using recombinant gag and env expression products (Verschoor et al., 1993). Anti-cell antibodies responses were measured in an immunofluorescence assay (IFA) using uninfected CRFK cells or thymocytes as antigen. Briefly, 96-well microtitre plates were coated with poly-L-lysine (Sigma) and $10^{5}$ cells $\mathrm{cm}^{-2}$ were seeded in the wells. For the quantitation of antibody levels against intracellular antigens cells were allowed to attach and fixed with $100 \mu \mathrm{l}$ per well of $96 \%$ ethanol at $-70^{\circ} \mathrm{C}$ followed by incubation for $2 \mathrm{~h}$ at room temperature (RT). Antibodies to surface antigens were quantified on cells that had been fixed with $100 \mu 1$ per well of $0.1 \%$ paraformaldehyde in PBS for $30 \mathrm{~min}$ at $4^{\circ} \mathrm{C}$. After fixation the cells the wells were blocked with $5 \%$ skimmed milk powder in PBS for $30 \mathrm{~min}$ at RT. Subsequently, the plates were emptied and incubated with $60 \mu \mathrm{l}$ of serum dilution per well at $37^{\circ} \mathrm{C}$. The plates were then incubated with $60 \mu \mathrm{l}$ of appropriately diluted FITC-conjugated rabbit-anti-cat-immunoglobulin (Nordic) per well for $1 \mathrm{~h}$ at $37^{\circ} \mathrm{C}$. Between each step in the IFA procedure the plates were washed twice with PBS. Presence of anti-cell antibodies was determined by immunofluorescence microscopy. Virus-neutralizing antibodies were determined using a neutralization assay on CRFK cells developed in our laboratory (De Ronde et al., 1994). 


\subsection{Determination of virus load}

Ten-fold dilutions of PBLs from vaccinated cats were co-cultivated in triplicate with thymocytes and virus replication was determined after 12 days by using a 24 ELISA. The virus load was expressed as $\mathrm{TCID}_{50}$ per $10^{4}$ PBLs.

\subsection{Major histocompatibility complex (MHC) typing}

Immunoprecipitates of Class I and II feline lymphocyte antigens were analysed by onedimensional jsoelectric focusing (ID-IEF) as described by Joosten et al. (1988, 1989). Briefly, membrane proteins of $\left[{ }^{35} \mathrm{~S}\right]$ methionine labelled cells were extracted using Triton X-114 (Class I antigens) or NP40 (Class II antigens). After preclearing, the Class I molecules were precipitated using monoclonal antibodies W6/32 (Parham et al., 1979) and HC10 (Stam et al., 1986) directed to native and denatured human Class I antigens, respectively. Class II molecules were precipitated using a polyclonal antiserum against human DR and DQ that also reacts with feline Class II antigens (Neefjes et al., 1986), and monoclonal antibody TH14B that recognizes Class II molecules from several species (Davis et al., 1987).

\subsection{Polymerase chain reaction $(P C R)$}

Genomic DNA was isolated from PBLs according to Boom et al. (1990). A 168 bp region of the FIV $\mathrm{p} 24$ coding region was amplified in a nested PCR. The amplification was carried out with DNA equivalent to $10^{5}$ PBLs in a $100 \mu \mathrm{l}$ reaction containing $50 \mathrm{mM} \mathrm{KCl}$, $10 \mathrm{mM}$ Tris- $\mathrm{HCl}$ (pH 9.0) $0.1 \%$ Triton $\mathrm{X}-100,1.9 \mathrm{mM} \mathrm{MgCl}_{2}, 100 \mathrm{ng}$ of each primer, $200 \mu \mathrm{M}$ of each dNTP, and 2.5 units Taq polymerase. The first PCR was carried out for 35 cycles $\left(1 \mathrm{~min} 95^{\circ} \mathrm{C}, 1 \mathrm{~min} 55^{\circ} \mathrm{C}, 1 \mathrm{~min} 72^{\circ} \mathrm{C}\right.$ ), upon which $10 \mu \mathrm{l}$ were transferred to the second PCR running at a $\mathrm{MgCl}_{2}$ concentration of $3.5 \mathrm{mM}$. The outer primers used were $5^{\prime}-$ GGATTAACTCAAGAACAGCAAGCAG-3' (FIV-Petaluma gag gene position 13381362; GenBank data base accession number M25729) and 5'-GTTTTAAATATAGCTTAACTTCAGCTG-3' (pos. 1566-1540). The inner primer set consisted of 5'-C.AAGATTTGCACCAGCTAGGATGC-3' (pos. 1365-1389) and 5'-TGTTCTTGATCTATTTGGGC-3' (pos. 1534-1515).

\section{Results}

\subsection{Antibody response to vaccination}

The antibody responses in the vaccinated cats to the gag and env gene products are shown in Table 1 . At challenge all CRFK-UT113 vaccinated cats had high anti-gag protein antibody titres equalling to or exceeding those detectable in naturally FIV-infected cats. The levels of antibodies directed against the envelope precursor were 8- to 16-fold lower than those in the positive control serum. The responses in the thymocyle-UT113 vaccinated cats were weak, two animals (Cats 7 and 10) showing hardly detectable amounts of antibodies against 
Table 1

Antibody response in vaccinated cats at time point of challenge ( $t=0$ weeks)

\begin{tabular}{|c|c|c|c|c|}
\hline Vaccine & Cat & gag & env & VN \\
\hline \multirow[t]{5}{*}{ CRFK-UT 113} & 1 & 32768 & 256 & 128 \\
\hline & 2 & 8192 & 256 & 256 \\
\hline & 3 & 4096 & 512 & 128 \\
\hline & 4 & 8192 & 256 & 128 \\
\hline & 5 & 8192 & 512 & 512 \\
\hline \multirow[t]{5}{*}{ Thymocyte-UT113 } & $6^{\circ}$ & 1024 & 32 & 64 \\
\hline & 7 & 64 & 8 & $<16$ \\
\hline & 8 & 512 & 64 & 16 \\
\hline & 9 & 2048 & 256 & 16 \\
\hline & 10 & 64 & 8 & 16 \\
\hline \multirow[t]{3}{*}{ CRFK } & 11 & $<8$ & $<8$ & $<16$ \\
\hline & 12 & $<8$ & $<8$ & $<16$ \\
\hline & 13 & $<8$ & $<8$ & $<16$ \\
\hline \multirow[t]{3}{*}{ Thymocyte } & 14 & $<8$ & $<8$ & $<16$ \\
\hline & 15 & $<8$ & $<8$ & $<16$ \\
\hline & 16 & $<8$ & $<8$ & $<16$ \\
\hline \multirow[t]{4}{*}{ PBS } & $17^{a}$ & ND & ND & ND \\
\hline & 18 & $<8$ & $<8$ & $<16$ \\
\hline & 19 & $<8$ & $<8$ & $<16$ \\
\hline & pos. control & 4096 & 4096 & 256 \\
\hline
\end{tabular}

gag, anti-gag antibody titre.

env, anti-env antibody titre.

$\mathrm{VN}$, virus neutralization titre.

pos. control, serum of an experimentally infected cat.

"Animal died during vaccination.

the viral structural proteins. The weaker response found in the thymocyte-UT113 vaccinated cats may reflect the lower viral antigen dose administered.

Although the titres of antibody directed against the envelope were much lower in CRFKUT113 vaccinated cats than in the FIV-infected, positive control cat, the levels of virusneutralizing (VN) antibodies were comparable (Table 1). Cats that had received the FIV-infected thymocyte vaccine had no (Cat 7) or very low VN titres.

Antibodies to internal and surface-exposed cellular antigens were demonstrated in an IFA using fixed uninfected cells. The results are shown in Table 2. Antibodies to cell antigens were found in all cats that had received a fixed-cell vaccine.

\subsection{Detection of viraemia after challenge}

Virus isolation from PBLs was attempted at regular intervals starting at the moment of challenge. Virus was readily isolated from the PBL samples, except from the PBLs of Cats 7, 10 and 15 . PBLs collected at 25 weeks after infection from these apparently uninfected 
Table 2

Anti-cell antibody titres $\left(\log ^{4}\right.$ titre $)$ in sera from vaccinated cats as determined in an IFA

\begin{tabular}{|c|c|c|c|c|c|c|c|c|c|}
\hline \multirow[t]{3}{*}{ Vaccine } & \multirow[t]{3}{*}{ Cat } & \multicolumn{4}{|c|}{$t=-9$ weeks } & \multicolumn{4}{|c|}{$t=0$ weeks } \\
\hline & & \multicolumn{4}{|c|}{ CRFK cells Thymocytes } & \multicolumn{4}{|c|}{ CRFK cells Thymocytes } \\
\hline & & $\mathrm{PF}$ & $\mathrm{EtOH}$ & $\mathrm{PF}$ & $\mathrm{EtOH}$ & $\mathrm{PF}$ & $\mathrm{EtOH}$ & $\mathrm{PF}$ & $\mathrm{EtOH}$ \\
\hline \multirow[t]{5}{*}{ CRFK-UT113 } & 1 & $<2$ & $<3$ & 4 & 3 & 4 & 4 & 9 & 4 \\
\hline & 2 & $<2$ & $<3$ & 3 & 4 & 4 & 5 & 9 & 4 \\
\hline & 3 & $<2$ & $<3$ & 3 & 4 & 5 & 5 & 8 & 4 \\
\hline & 4 & $<2$ & $<3$ & 3 & 3 & 4 & 5 & 9 & 4 \\
\hline & 5 & $<2$ & $<3$ & 4 & 4 & 4 & 5 & 10 & 3 \\
\hline \multirow[t]{5}{*}{ Thymocyte-UT113 } & 6 & $<2$ & $<3$ & 4 & 4 & $<2$ & 3 & 4 & 4 \\
\hline & 7 & $<2$ & $<3$ & 3 & 4 & $<2$ & 3 & 3 & 4 \\
\hline & 8 & $<2$ & $<3$ & 3 & 4 & $<2$ & 3 & 2 & 3 \\
\hline & 9 & $<2$ & $<3$ & 3 & 3 & $<2$ & 5 & 5 & 3 \\
\hline & 10 & $<2$ & $<3$ & 3 & 3 & $<2$ & 3 & 4 & 3 \\
\hline \multirow[t]{3}{*}{ CRFK } & J] & $<2$ & $<3$ & 3 & 3 & $<2$ & 5 & 7 & 3 \\
\hline & 12 & $<2$ & $<3$ & 4 & 4 & $<2$ & 5 & 10 & 3 \\
\hline & 13 & $<2$ & $<3$ & 4 & 4 & $<2$ & 6 & 10 & 3 \\
\hline \multirow[t]{3}{*}{ Thymocyte } & 14 & $<2$ & $<3$ & 3 & 3 & $<2$ & 3 & 3 & 3 \\
\hline & 15 & $<2$ & $<3$ & 3 & 3 & $<2$ & 3 & 4 & 4 \\
\hline & 16 & $<2$ & $<3$ & 4 & 4 & $<2$ & 3 & 4 & 4 \\
\hline \multirow[t]{2}{*}{ PBS } & 18 & $<2$ & $<3$ & 3 & 3 & $<2$ & 3 & 4 & 4 \\
\hline & 19 & $<2$ & $<3$ & 3 & 3 & $<2$ & 3 & 4 & 4 \\
\hline
\end{tabular}

PF, paraformaldehyde-fixed cells.

$\mathrm{EtOH}$, ethanol-fixed cells.

animals and from the FIV-positive animals 9 and 14 were used for DNA isolation and PCR analysis. Specific DNA amplification was not detectable in the samples from the virus isolation-negative cats while Cats 9 and 14 tested positive in the nested PCR. Protection was also evidenced by the lack of antibody response after challenge in Cats 10 and 15 (results not shown). Cat 7, however, did produce low-titred antibody to the core proteins of FIV (Fig. 1); its titre rose in the first 2 weeks after challenge and remained at a low level for more than 6 months.

Although most cats were not protected against FIV infection, the immunizations had some effect. Titration of PBLs in uninfected thymocytes was performed to determine whether the virus load was reduced. They were determined (as $\mathrm{TCID}_{50}$ per $10^{4} \mathrm{PBLs}$ ) at 9 and 25 weeks after challenge (a.c.) and are presented in Table 3. Using the Mann-Whitney test we found that the viral load in PBLs from cats after FIV-infected CRFK cell vaccination was significantly lower than in the other animals $(P=0.02$ and $P=0.005$ at 9 and 25 weeks a.c., respectively). The decreased virus load coincided with a high neutralizing antibody titre at the time-point of challenge. 


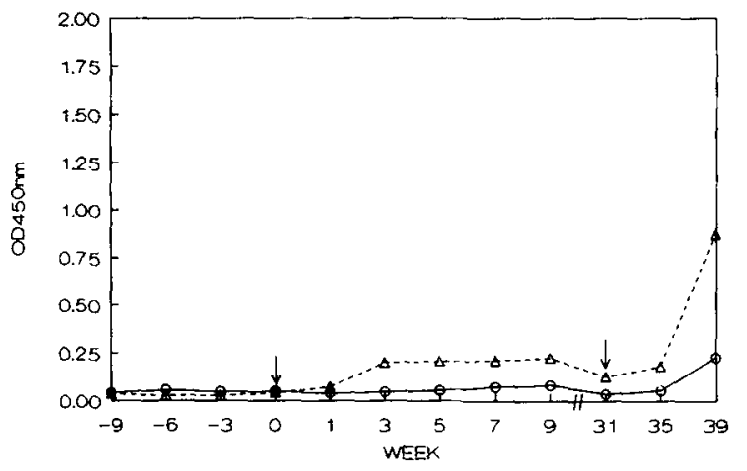

Fig. 1. FIV-specific antibody response of Cat 7 to core antigen:- $--;$ to envelope antigen: - $\bigcirc-$. Arrows indicate time points of the first ( $t=9$ weeks) and second ( $t=31$ weeks) challenge.

\subsection{Second challenge of protected cats}

Cats 7,10 and 15 were re-challenged with $10 \mathrm{CID}_{50}$ of FIV-UT113 at 31 weeks after the first challenge and, 5 weeks later, FIV could be isolated from Cat 7. Infection was also evident from a rise in titres of FIV-specific antibodies in this animal (Fig. 1). The other two animals again remained FIV-negative as was evidenced by the inability to isolate virus from PBLs and the lack of seroconversion (data not shown). PCR analysis of DNA from PBLs confirmed the protection of the animals against this low challenge dose of FIV-UT113

Table 3

Virus load titration in thymocytes

\begin{tabular}{|c|c|c|}
\hline \multirow[t]{2}{*}{ Cat } & \multicolumn{2}{|c|}{$\mathrm{TCID}_{50}$ per $10^{4} \mathrm{PBLs}$} \\
\hline & $t=9$ weeks ${ }^{i}$ & $t=25$ weeks ${ }^{a}$ \\
\hline 1 & 22.4 & 3.6 \\
\hline 2 & 2.2 & 1.8 \\
\hline 3 & 1.8 & 1.4 \\
\hline 4 & 2.0 & 1.8 \\
\hline 5 & 2.8 & 4.5 \\
\hline 6 & 6.7 & 7.1 \\
\hline 7 & - & - \\
\hline 8 & 20.4 & 3.6 \\
\hline 9 & 10.2 & 14.1 \\
\hline 10 & - & - \\
\hline 11 & 10.2 & 11.2 \\
\hline 12 & 35.5 & 5.6 \\
\hline 13 & 5.6 & 5.6 \\
\hline 14 & 26.6 & 14.1 \\
\hline 15 & - & - \\
\hline 16 & 33.1 & 4.5 \\
\hline 18 & 35.5 & 8.9 \\
\hline 19 & 7.1 & 11.2 \\
\hline
\end{tabular}

"Weeks after challenge. 
Table 4

MHC typing of (partially) protected cats and of the thymocytes used for vaccine production

\begin{tabular}{lll}
\hline & MHC Class I & MHC Class II \\
\hline Cat 7 & $1 / 3$ & $1 / 2$ \\
Cat 10 & $1 / 2$ & $1 / 2$ \\
Cat 15 & $3 /-$ & $1 / 3$ \\
Thymocytes & $3 / 2$ & $4 /-$ \\
\hline
\end{tabular}

${ }^{\mathrm{a}}$ Different $\mathrm{MHC}$ haplotypes are indicated by arbitrary numbers. -, indicates either homozygosity at a particular $\mathrm{MHC}$ region or possible failure to detect the second haplotype.

as no specific amplification was detectable in the DNA samples of these cats (data not shown ).

\subsection{Biochemical typing of $M H C$ antigens}

To investigate the involvement of a MHC-haplotype specific response in protection we determined the MHC Class I and II haplotypes of the protected animals and the thymocytes that were used in the vaccines. Antibodies cross-reactive with MHC Class I and Class II antigens from different species were used for this study. Using 1D-IEF, Class I and Class II haplotype associated banding patterns could be defined making use of the limited family data available. The different banding patterns were arbitrarily assigned numbers $1-3$ for Class I and 1-4 for Class II. So far, typing results are preliminary and the haplotype associated banding patterns need to be confirmed by family segregation studies. Typing results for the (partially) protected cats and the thymocytes used for vaccination are shown in Table 4. The animals do not appear to have a Class I haplotype in common but each cat shares one type with the thymocytes. Class II haplotype 1 was shared by all animals but was not detectable on the thymocytes.

\section{Discussion}

In earlier vaccination studies cats had been protected against a homologous (FIV-Petaluma) and a heterologous challenge (FIV-Dixon) with a protection rate of more than $90 \%$ (Yamamoto et al., 1991, 1993). Wc cannot confirm these data; however, we have performed our vaccination trial using a different virus isolate and different feline cell types. Eight out of ten cats that had been vaccinated with FIV-infected cells developed a significant antibody response to viral proteins. Although the anti-envelope responses in the CRFK-UT113 vaccinated cats were considerably lower than in FIV-infected cats (Table 1 and E. Verschoor, 1993, unpublished observations) the VN titres were comparable. This indicates that the FIV-infected CRFK cells were able to efficiently induce virus-neutralizing antibodies. It can be excluded that antibodies directed against the cells interfered in the CRFK cellbased neutralization assay since this should have resulted in VN titres also in the CRFK control cats.

After challenge eight out of the ten cats vaccinated with FIV-infected cells and five out of the six uninfected-cell vaccinees became infected. An effect of the immunizations was 
observed in the cats vaccinated with the CRFK-UT113 cell vaccine. Virus load in PBLs from these animals was significantly reduced and correlated with high neutralization titres in the sera. Antibodies can protect cats against FIV infection: sera from vaccinated and protected animals also protected against challenge with FIV-Petaluma (Hohdatsu et al., 1993). Inability to induce a high anti-envelope antibody titre may explain the difference in success between our study and the experiments performed by Yamamoto and co-workers. A high level of envelope protein is expressed in the FL4 cells used by Yamamoto et al. as compared with other cell types (Hosie, 1994). Loss of the non-covalently attached surface protein during purification was found to be much greater for FIV-UT113 infected cells than for FIV-Petaluma (H. Egberink, 1992, unpublished observations). In addition, the Syntex adjuvant used in the successful trials may also have induced a qualitatively and quantitatively different immune response than the water/oil emulsion used in our study.

Surprisingly, the animals that hardly produced antibody to vaccination with the thymocyte-UT113 preparation (Cats 7 and 10) and one thymocyte-control animal (Cat 15) remained uninfected after the first challenge. Cat 7 responded by producing a low level of antibody to the viral core protein. No virus could be recovered from this cat and the antibody response remained low, suggesting a transient infection that had successfully been cleared. This animal was not able to withstand a second challenge 31 weeks after the first, while Cats 10 and 15 again remained uninfected. The mechanism by which these animals were (partially) protected remains unclear. Because the cats had no or only low levels of (neutralizing) antibodies to FIV at the moment of challenge these are probably not responsible for protection.

Monkeys have been protected against SIV infection after vaccination with uninfected human C.8166 cells (Stott, 1991). Immunodeficiency viruses can carry a variety of cellular antigens that became incorporated into the viral envelope during maturation (Arthur et al., 1992). Protection against SIV correlated with the presence of antibodies directed to MHC class I antigens (Chan et al., 1992); apparently antibody responses against cellular antigens exposed on the viral particle can prevent infection. The human cell line used in the SIV monkey studies induced a strong anti-cell response in the monkey recipient. In contrast, we used a homologous system employing feline cells to prepare both the challenge virus and the vaccines. However, antibodies directed to cellular antigens were detectable in the cat sera. Thus, despite the lack of correlation between protection and the total anti-cell antibody titre, antibodies directed to specific cellular antigens may have contributed to protection of the three animals.

Recently, a decreased risk of HIV infection was found to be associated with specific MHC Class I alleles (Plummer et al., 1993) indicating that resistance may have been genetically determined. Resistance as a result of MHC Class I or II polymorphism might explain the protection observed in our experiments. This may also be the reason for the decreased FIV-specific antibody response found in Cats 7 and 10. Cats 7, 10, and 15 shared a Class II haplotype, but preliminary MHC typing data indicate that this haplotype is also found the other animals. The MHC Class I haplotypes found on the thymocytes have been detected only on PBLs of Cats 7, 10, and 15. This similarity accounts for either one of the two haplotypes detectable on the cells but, no particular type is shared by all three animals. Thus, a straightforward explanation for the (partial) protection of the cats based on this MHC typing cannot be given. 
In conclusion, our fixed-cell vaccines did not protect most cats against FIV infection; however, the CRFK-UT113 vaccine did reduce the virus load in PBLs after challenge. Three cats vaccinated with fixed thymocytes remained uninfected via an as yet unknown mechanism.

\section{Acknowledgements}

This work was supported by Intervet International BV, Boxmeer, The Netherlands. The authors like to thank Thomas Vahlenkamp for performing PCR and Carla Kuiken for the statistical analysis of our data.

\section{References}

Arthur, L.O., Bess, J.W., Sowder, R.C., Benveniste, R.E.,Mann, D.L., Chermann, J.-C. and Henderson, L.E., 1992. Cellular proteins bound to immunodeficiency viruses: implications for pathogenesis and vaccines. Science, 258: 1935-1938.

Boom, R., Sol, C.J.A., Salimans, M.M.M., Jansen, C.L., Wertheim-van Dillen, P.M.E. and van der Noordaa, J.A., 1990. A rapid and simple method for purification of nucleic acids. J. Clin. Microbiol., 28: 495-503.

Chan, W.L., Rodgers, A., Hancock, R.D., Taffs, F., Kitchin, P., Farrar, G. and Liew, F.Y., 1992. Protection in simian immunodeficiency virus-vaccinated monkeys correlates with anti-HLA class I antibody response. J. Exp. Med., 176: 1203-1207.

Daniel, M.D., Kirchhoff, F., Czajak, S.C., Sehgal, P.K. and Desrosiers, R.C., 1992. Protective effects of a live attenuated SIV vaccine with a deletion in the nef gene. Science, 258: 1938-1941.

Davis, W.C., Marusic, S., Lewin, H.A., Splitter, G.A., Perryman, L.E., McGuire, T.C. and Gorham, J.R., 1987. The development and analysis of species specific and cross-reactive monoclonal antibodies to leucocyte differentiation antigens and antigens of the major histocompatibility complex for use in the study of the immune system in cattle and other species. Vet. Immunol. Immunopathol. 15: 337-376.

De Ronde, A., Stam, J.G., Boers, P., Langedijk, H., Meloen, R., Hesselink, W., Keldermans. C.E.J.M., Van Vliet. A.L.W., Verschoor, E.J., Horzinek, M.C. and Egberink, H.F., 1994. Antibody response in cats to the envelope proteins of feline immunodeficiency virus: identification of an immunodominant neutralization domain. Virology, 198: 257-264.

Egberink, H., Borst, M., Niphuis, H., Balzarini, J., Neu, H., Schellekens, H., de Clercq. E., Horzinek, M. and Koolen, M., 1990. Suppression of feline immunodeficiency virus infection in vivo by 9-(2-phosphonomethoxyethyl )adenine. Proc. Natl. Acad. Sci. USA, 87: 3087-3091

Egberink, H. and Horzinek, M.C., 1992. Animal immunodeficiency viruses. Vet. Microbiol., 33: 31 1-331.

Hohdatsu, T., Pu, R., Torres, B.A., Trujillo, S., Gardner, M.B. and Yamamoto, J.K., 1993. Passive antibody protection of cats against feline immunodeficiency virus infection. J. Virol., 67: 2344-2348.

Hosie, M., 1994. The development of a vaccine against feline immunodeficiency virus: a review. Br. Vet. J., 150: 25-39.

Hu, S.-L., Abrams, K., Barber, G.N., Moran, P., Zarling, J.M., Langlois, A.J., Kuller, L., Morton, W.R. and Benveniste, R.E., 1992. Protection of macaques against SIV infection by subunit vaccines of SIV envelope glycoprotein gp 160. Science, 255: 456-459.

Johnson, P.R., Montefiori, D.C., Goldstein, S., Hamm, T.E., Zhou, J., Kitov, S., Haigwood, N.L., Misher, L., London, W.T., Gerin, J.L., Allison. A., Purcell, R.H., Chanock, R.M. and Hirsch. V.M., 1992. Inactivated whole-virus vaccine derived from a proviral DNA clone of simian immunodeficiency virus induces high levels of neutralizing antibodies and confers protection against heterologous challenge. Proc. Natl. Acad. Sci. USA, 89: 2175-2179. 
Joosten, I., Oliver, R.A., Spooner, R.L., Williams, J.L., Hepkema. B.G., Sanders, M.F. and Hensen, E.J., 1988. Characterization of class I bovine lymphocyte antigens (BoLA) by one-dimensional iso-electric focusing. Anim. Genet., 19: 103-113.

Joosten, I., Sanders, M.F., van der Poel, A.. Williams, J.L., Hepkema, B.G. and Hensen, E.J., 1989. Biochemically defined polymorphism of bovine MHC class II antigens. Immunogenetics, 29: 213-216.

Neefjes, J.J., Hensen, E.J., de Kroon, T.1.P. and Ploegh, H.L., 1986. A biochemical characterization of feline MHC products: unusually high expression of class II antigens on peripheral blood lymphocytes. Immunogenetics. 23: $341-347$.

Parham, P., Barnstable, C.J. and Bodmer, W., 1979. Use of a monoclonal antibody (W6/32) in structural studies of HLA-A, B, C antigens. J. Immunol., 123:342-349.

Plummer, F.A., Fowke, K., Nagelkerke, N.J.D., Simonsen, J.N., Bwayo, J. and Ngugi, E., 1993. Evidence of resistance to HIV among continuously exposed prostitutes in Nairobi, Kenya. IXth Int . Conf. AIDS, (Abstract)

Stam, N.J.. Spits, H. and Ploegh, H.L., 1986. Monoclonal antibodies raised against denatured HLA-B locus heavy chains permit biochemical characterization of certain HLA-C locus products. J. Immunol., 137: $2299-2306$.

Stott. E.J., 1991. Anti-cell antibody in macaques. Nature, 353: 393.

Verschoor, E.J., Van Vliet, A.L.W., Egberink, H.F., Hesselink, W., Horzinek, M.C. and De Ronde, A., 1993. Expression of feline immunodeficiency virus gag and ent precursor proteins in Spodoptera frugiperda cells and their use in immunodiagnosis. J. Clin. Microbiol., 31: 2350-2355.

Yamamoto, J.K., Okuda, T., Ackley, C.D., Louie, H., Pembroke, E., Zochlinski, H., Munn, R.J. and Gardner, M.B.. 1991. Experimental vaccine protection against feline immunodeficiency virus. AIDS Res. Hum. Retrnviruses. 7: $911-922$.

Yamamoto, J.K., Hohdatsu, T., Olmsted, R.A., Pu, R.. Louie, H., Zochlinski, H.A., Acevedo. V., Johnson, H.M., Soulds, G.A and Gardner, M.B., 1993. Experimental vaccine protection against homologous and heterologous strains of feline immunodeficiency virus. J. Virol., 67: 601-605. 